\title{
Shifts in the gut and genital microbiome during natural SIV infection in vervet monkeys
}

Anna J Jasinska

Tien S. Dong

Venu Lagishetty

William Katzka

Jonathan P. Jacobs

Christopher A Schmitt

Jennifer Danzy Cramer

Dongzhu Ma

Willem G Coetzer

J. Paul Grobler

Trudy R Turner

Nelson Freimer

Ivona Pandrea

Cristian Apetrei

Video Byte

Keywords: SIV, microbiome, Proteobacteria, Succinivibrio, acute infection, primate, HIV, vervet, monkey, Microbiome

Posted Date: February 25th, 2021

DOI: https://doi.org/10.21203/rs.3.rs-275917/v1

License: (c) (i) This work is licensed under a Creative Commons Attribution 4.0 International License. Read Full License 


\section{Abstract}

HIV affects 38 million people worldwide, and a cure remains elusive. One important factor in transmission and pathogenesis lies outside the virus: the microbiome of the gut and genital surfaces is increasingly recognized as a key player during HIV infection, affecting inflammation and microbial translocation. In an effort to better understand the effects of microbes on health during infection, researchers turned to an animal model. Vervet monkeys are a natural host for a closely related virus, simian immunodeficiency virus (SIV). Because they have faced SIV for hundreds of thousands of years, the monkeys have co-evolved with the virus, allowing vervets to have nonprogressive SIV infection. By evaluating the microbiota of SIV-infected vervets, the researchers sought to determine what microbeassociated factors protected vervets against AIDS. Characterization of fecal, rectal, vaginal, and penile microbiomes in vervets from heavily SIV-infected areas in South Africa. demonstrated that gut microbial diversity increased after SIV infection. and alterations were also observed in community composition and functionality. These results suggest that SIV-infected vervets have different microbial responses to infection than HIV-infected humans. offering insight into how therapies adjusting the microbial response may affect microbial translocation and disease progression. 